This item was submitted to Loughborough's Research Repository by the author.

Items in Figshare are protected by copyright, with all rights reserved, unless otherwise indicated.

\title{
A philosophy for a performance specification for road foundations
}

PLEASE CITE THE PUBLISHED VERSION

PUBLISHER

(C) Thomas Telford

LICENCE

CC BY-NC-ND 4.0

REPOSITORY RECORD

Rogers, C.D.F., Paul R. Fleming, and Matthew W. Frost. 2019. "A Philosophy for a Performance Specification for Road Foundations". figshare. https://hdl.handle.net/2134/3598. 
This item was submitted to Loughborough's Institutional Repository by the author and is made available under the following Creative Commons Licence conditions.

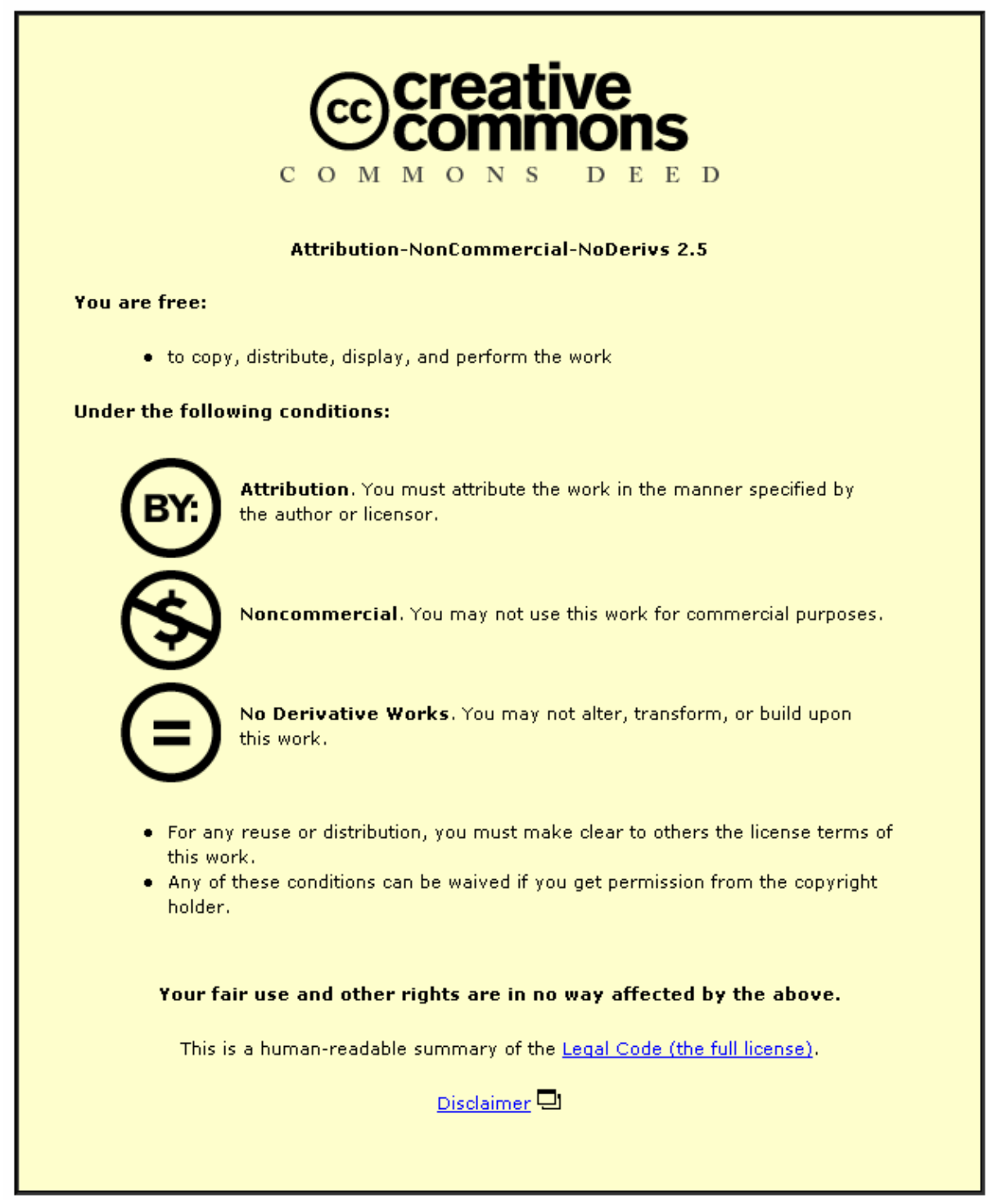

For the full text of this licence, please go to: http://creativecommons.org/licenses/by-nc-nd/2.5/ 


Proceedings of the Institution of
Civil Engineers
Transport I57
August 2004 Issue TR3
Pages 143-I5|
Paper 13098
Received I2/I I/2002
Accepted I I/I I/2003
Keywords:
foundations/roads \& highways

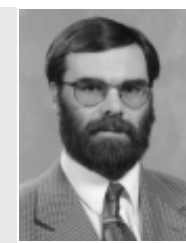

C. D. F. Rogers Professor of Geotechnical Engineering, Department of Civil Engineering, University of Birmingham, UK

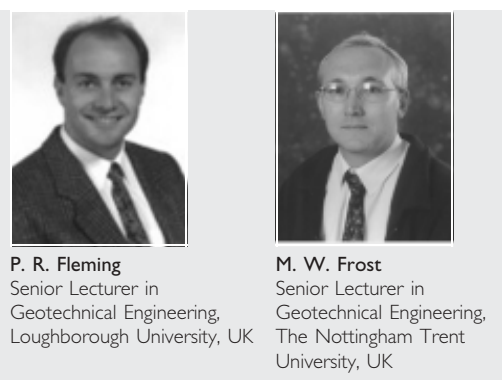

University, UK

\section{A philosophy for a performance specification for road foundations}

C. D. F. Rogers PhD, CEng, MICE, MI, P. R. Fleming BEng, MIHT, and M. W. Frost

The road foundation layers perform several functions both during construction and when the road is in service, for example load-spreading, temporary haul routes, and a base for the overlying construction layers. The critical loading condition is usually directing trafficking where the applied stresses are greatest. The capping and subbase layers during construction require adequate stiffness and strength to resist these stresses. The current UK specification for road foundations is based on a recipe approach, and, unless permission is granted to use an analytical design, the pavement foundation designs are based entirely on the California Bearing Ratio (CBR) to characterise the subgrade, capping and sub-base materials. Here CBR is used as an index of both material strength and stiffness, although it measures neither directly. Such an approach is potentially inefficient and does not readily facilitate the use of new and marginal materials or alternative design procedures. Recent technical advances in laboratory and in situ testing of pavement foundation materials now allow the performance parameters of stiffness, strength and resistance to permanent deformation to be measured both for design and during construction. This in turn enables a performance-based specification for road foundation layers to be introduced to provide some assurance of the as-constructed quality, and by permitting the use of secondary or recycled aggregates, to contribute to the parallel goal of sustainable construction. This paper sets out an idealised philosophy for a performance-based specification for road foundations, examines the individual elements of the specification in relation to current knowledge and makes recommendations for a phased introduction alongside CBR-based methods.

\section{INTRODUCTION}

The accurate analysis of road pavement structures is severely compromised by the complex nature of the materials involved, the complex interaction between material layers, and the complex pattern of loading to which the materials are subjected. ${ }^{1}$ Accurate analysis is further complicated by the change in material properties with age and environmental conditions. This complexity, combined with a lack of knowledge of, and ability to measure routinely, the functional material parameters needed for a full mechanistic design process, resulted in the development worldwide of recipe specifications for road pavement design and construction based on indices of performance. ${ }^{2}$ The recipe specification results from the classical empirical engineering approach of design and construction on the basis of long-term monitoring of fullscale test roads and index tests, and development of a set of rules that avoids failure and maximises life. Such design approaches work well where the ambient conditions are similar and there is consistency between the materials and methods that are used. However, where the conditions change for whatever reason (i.e. loading magnitudes or patterns change, novel materials are proposed, etc.), the empirical methods become less assured and failures are possible until sufficient new experience is gained. This is clearly inefficient, and mechanistic models are preferred where it is possible to create them with confidence. The upper, bound structural layers present their own challenges, but this paper focuses on the provision of adequate road foundations, which consist of the sub-base, capping (where required) and subgrade soils. This is admissible because the foundation design is traditionally carried out separately from that of the overlying bound layers. ${ }^{3,4}$ Although the adequate life-long drainage of the foundation is of primary importance, this aspect is not considered in any detail in this paper.

The current UK specification for road foundations is based on a recipe approach, whereby selected materials are laid and compacted with specified plant in a specified manner to achieve a minimum level of performance. ${ }^{4}$ Unless permission is granted to use an analytical design, the pavement foundation designs are based entirely on the use of the California Bearing Ratio (CBR) to characterise the subgrade, capping and sub-base materials. Here CBR is used as a measure of both material strength and stiffness, although the test itself evidently provides only an index of performance by its nature (as discussed below). Thus in spite of the fact that the use of CBR as a performance parameter is widely acknowledged as being not wholly satisfactory, CBR has been correlated with pavement performance in many countries over many years and provides a trusted empirical indicator of material behaviour. Many years of research into its use at the Transport (previously Road) Research Laboratory resulted in sophisticated advice on its use in UK practice. ${ }^{5}$ 
A CBR-based approach is unlikely, however, to allow for efficient use of plant and materials, whether new or traditional, and/or the use of alternative (and innovative) design procedures. In addition, considerable advances have been made in the understanding and measurement of road foundation material properties over the past 30 years that potentially allow engineers to take advantage of the fully analytical design models that have been developed in parallel. Similarly, recent technical advances in in situ testing of pavement foundation materials now allow the performance parameters of stiffness, strength and resistance to permanent deformation (a term used to recognise the composite action of the materials) to be measured during construction. ${ }^{6-8}$ This in turn enables a performance-based specification for road foundation layers to be introduced, hence providing a greater efficiency of site operations and providing some assurance of the as-constructed quality, as well as facilitating the use of previously untried materials.

This paper aims to define the various functions of a road foundation, summarise the key performance parameters for road foundation materials (while demonstrating the limitations of CBR as a design parameter), and recommend ways in which they can be measured before, during and after construction. This information is presented in the form of a philosophy for a performance-based specification for road foundations. The additional research required to facilitate the formulation and validation of such a specification is then outlined. This research includes laboratory testing, theoretical analysis and field trials on both live sites and on specially constructed trial sections of road foundation, the results of the fieldwork being compared with designs based on both the CBR approach and the analytical approach. ${ }^{9}$ The paper concludes with a brief discussion of current work that is being conducted to facilitate the implementation of the performance specification in routine practice for motorways and trunk roads.

\section{FUNCTIONS OF A ROAD FOUNDATION}

The sub-base and, where necessary, capping that is constructed over the prepared subgrade perform several functions (see Fig. 1):

(a) They must support construction vehicles during the construction of the overlying layers, and in some cases must act as a haul road for the transportation of materials along the site. In doing this they must not deform excessively themselves, as permanent weakening (i.e. loss of compacted structure) would occur. In addition, they must spread the applied surface stresses sufficiently to reduce the stresses transmitted to the subgrade to a level that will not cause significant permanent deformation (i.e. to avoid subgrade rutting, thus possible ponding of water and/or weakening of the subgrade due to shear strain).

(b) They must provide an adequately even and stiff base for the laying and compacting of the overlying pavement layers.

(c) They must provide adequate support to the overlying (bound) layers when the road pavement is in use, and must distribute the stresses transmitted from these overlying layers to create an acceptably low stress at the surface of the subgrade. This is to avoid incremental pavement

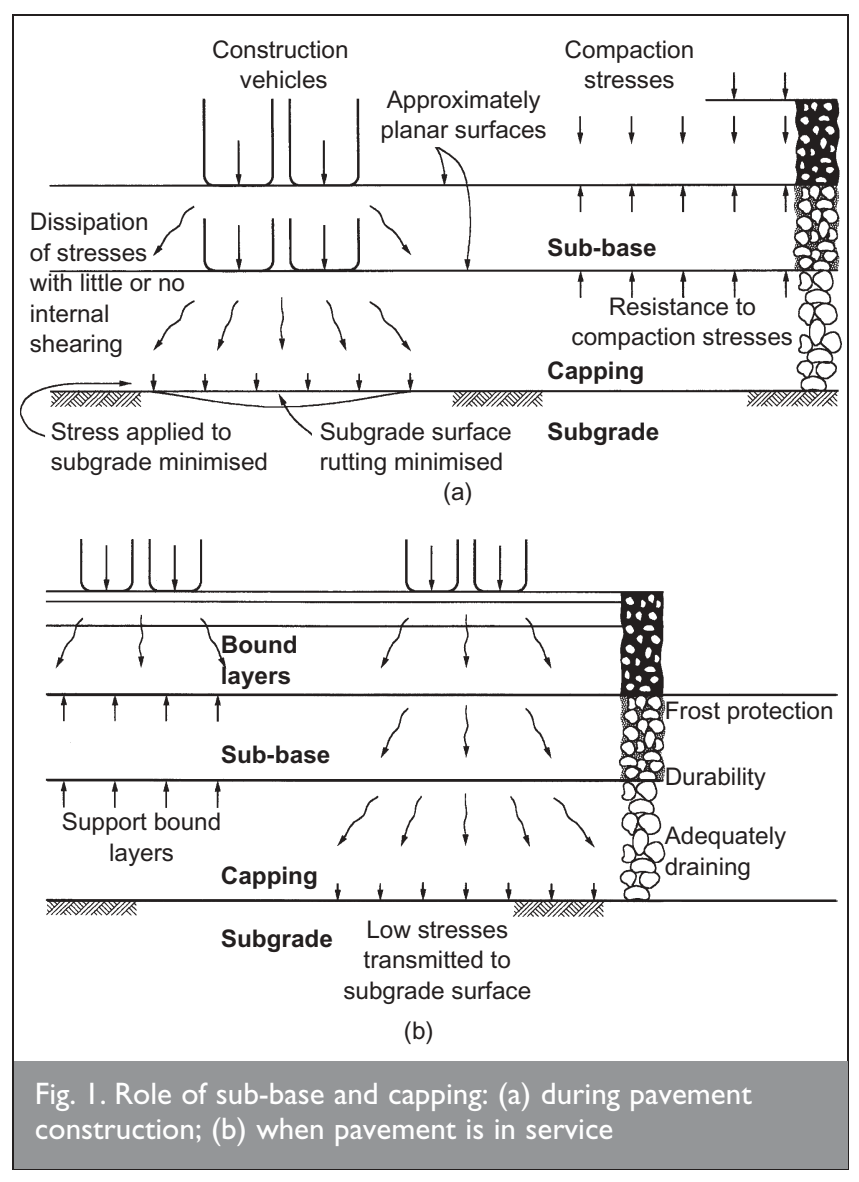

deterioration under very large numbers of repeated (small) stress applications.

(d) They must provide adequate frost protection to the subgrade, must not degrade, and must have adequate drainage capabilities.

The most serious loading condition occurs during construction because, although the number of stress applications during construction is relatively small, the magnitude of the applied stresses imparted by the construction traffic is very high relative to the in-service condition. As a consequence it is for this condition that the foundation layers are primarily designed. It is important also, however, to consider the effects that environmental changes could have in the long term, and to ensure that designs are sufficiently robust to deal with these. In defining these characteristics, it is assumed that the drainage is effective in both the short and long term.

\section{THE CALIFORNIA BEARING RATIO (CBR)}

The CBR of a soil or granular material is determined in the laboratory essentially by compacting the material into a rigid mould (150 $\mathrm{mm}$ diameter, $150 \mathrm{~mm}$ deep) and recording the force required to advance a centrally located $50 \mathrm{~mm}$ diameter plunger by $2.5 \mathrm{~mm}$ and $5.0 \mathrm{~mm}$ into the upper surface of the specimen. The specimen can then be inverted and the process of penetration repeated. The force required is divided by that required to penetrate a standard crushed rock, the percentage being the CBR. It is immediately apparent, therefore, that shearing must take place within the specimen to allow the plunger to penetrate. However, it is equally apparent that the degree of penetration is relatively small and that the plunger is relatively large in comparison with the sample diameter. 
Therefore the stiffness of the sample will significantly influence the results. For a strong material such as a crushed rock it is more 'stiffness related', whereas for a wet clay it is more 'strength related'. ${ }^{10}$ However, where its measurement is more 'stiffness related' it infers stiffness at larger strains and a lower strain rate than that caused by the structural loading sustained. In addition it does not model the application of repeated loading that occurs under trafficking. ${ }^{11}$ The test does not guarantee failure of the material under the plunger, and thus cannot be regarded as a true measure of strength either. ${ }^{12}$

The CBR is consequently an index of material competence that is influenced both by strength and by stiffness, but is a true measure of neither, as acknowledged in DMRB: ${ }^{4}$

The CBR is not a direct measure of stiffness modulus or of shear strength but it is widely used and considerable experience with it has been developed. It thus provides a common means of comparison.

Much research has been carried out to correlate CBR with true performance parameters for use in design. For example, Powell et al. ${ }^{5}$ suggest a relationship between elastic (or stiffness) modulus and CBR for a range of CBR values of $2-12 \%$. However, it is evident from soil mechanics principles that any such relationship can, at best, only be approximate, and this was demonstrated clearly by Hight and Stevens ${ }^{12}$ and Brown et al. ${ }^{11}$ in their studies on saturated clays. Indeed, Kleyn et $a l{ }^{13}$ have shown CBR to be strongly correlated to shear strength, as measured by the dynamic cone penetrometer (DCP). The CBR, therefore, is not a suitable parameter to use either for laboratory testing to feed analytical design models or in-situ as proof of performance. Nevertheless, it remains a parameter that practising engineers relate to well, and therefore must feature in any process of introduction of a new performance-based specification as a parallel indicator so that the experience gained in its use can be transferred. Note, however, that the CBR test is rarely carried out in situ and, in addition, suffers from major difficulties when used on coarse materials.

\section{PERFORMANCE PARAMETERS}

\section{I. Direct performance parameters}

It is evident from the above discussion that the primary performance parameters are elastic stiffness and strength/ resistance to permanent deformation. These parameters ideally need to be measured prior to design, either from representative samples taken from site or in situ during the site investigation, for both the subgrade and the proposed capping and sub-base. They also need to be measured in situ post-construction on the same materials to confirm that the desired (i.e. design) properties have been achieved. However, there are several factors that affect these measurements. ${ }^{14}$ It is widely recognised that there is no unique measurement of resilient elastic stiffness of a soil or granular aggregate, and thus any measurement must be qualified by the conditions under which it is measured. ${ }^{7,8,15}$ This includes the influences of stress and strain dependence, and for some materials strain rate dependence and even temperature dependence. There is also a large material dependence influence to take into account. For subgrade soils, their current state and stress history are clearly both important, but potential environmental changes (particularly water content) and the degree of disturbance from the undisturbed state will also be major influences on the measurement of elastic stiffness. For imported granular materials and stabilised soils the current water content (and potential for any change) and the depth in the layer (i.e. how well the materials were compacted when originally constructed) will both influence the value of stiffness. In addition, the stiffness that any one material can achieve will be dependent on that of the material that underlies it, and thus the materials cannot be considered in isolation.

In the case of strength/resistance to permanent deformation there is a similarly large dependence on stress and strain, and for some materials strain rate and temperature, as plastic strains accumulate under the action of repeated loading. There are also dependences on the material state and its potential for change. In this case, however, the dependence on the behaviour of the adjacent (underlying) layer properties is even greater, such that the strength taken in isolation can sometimes be a highly misleading indicator of the performance in situ. It is for this reason that the term 'resistance to permanent deformation' is included in the discussion herein.

Consequently the measurements of the relevant parameters should take place under conditions that match those to which they will be subjected in situ as closely as possible. For stiffness measurement, the frequency, rate and magnitude of loading together with the size of the loaded area should be as close as possible to those likely to be experienced. ${ }^{7,15}$ Additional factors such as rotation of principal stresses, although they should also ideally be simulated, are practically problematic for stiffness measurement and have to be ignored. This is acceptable in the case of elastic stiffness. However, in the case of strength/resistance to permanent deformation, where the materials undergo shearing, it is not acceptable to ignore such factors. ${ }^{16,17}$ As research into the mechanisms that lead to the development of rutting in twolayer systems is not well advanced, and the ability to model and predict rutting is consequently lacking, application of individual material strength measurements to characterise the tendency to rutting is not feasible. It is thus considered necessary to observe the effects of rolling wheel loading directly.

\subsection{Indirect performance parameters}

There are additional requirements of sub-base and capping materials that require the measurement of indirect performance parameters. Sub-base generally consists of an imported high-quality crushed rock, whereas capping can consist of an imported or locally won granular material, recycled asphalt planings or stabilised subgrade soils. ${ }^{18}$ These materials must be sufficiently robust not to degrade mechanically under compaction and trafficking stresses, and must be sufficiently durable to resist the environmental conditions pertaining over the life of the road. Thus there must be evidence of competence under aggregate durability (eg. $10 \%$ fines, aggregate abrasion and magnesium sulphate) testing. Aggregate durability testing is required no matter what type of specification is used, and will not be considered further herein. 


\section{A PERFORMANCE SPECIFICATION FOR ROAD FOUNDATIONS}

\section{I. The philosophy behind a performance specification for road foundations}

A performance specification aims to provide a client with an assurance that what is being paid for is being provided. This is preferable to an indirect measurement based upon experience, as this will only allow one to assume that the product should be acceptable. A performance specification can only be produced if there is a means of quantifying and measuring the performance of the as-constructed product. If this is possible, the client can then specify simply that the product, and the materials from which it is made, meet certain measurable criteria. This gives the manufacturer of the product freedom in both how it is made and what it is made from, which in turn opens up opportunities for innovation and/or savings. The production process is thereby made more efficient and concomitantly cheaper. In the case of road foundation construction, there are additional environmental benefits to be gained by widening the range of possible materials.

The design of the product, i.e. the road foundation, requires target values of the performance parameters to be defined. The target values, and hence design requirements, are different for the short-term (construction) condition than the long-term (in service) condition as a result of the different loading and environmental conditions, and are discussed later on. The specification is wholly dependent upon having accurate methods of performance measurement for samples of subgrade, capping and sub-base in the laboratory for design purposes, as well as parallel methods for measuring the performance of undisturbed and as-laid materials in situ. Although these will be referred to in developing the arguments in the following sections, they will not be discussed at length herein owing to space restrictions. Note also that the target values could be different depending upon which method of measurement is used, as the stress and strain conditions often vary between test methods.

The following philosophy has been developed on the basis that the subgrade is 'cohesive', rather than cohesionless, as the majority of UK subgrade soils are 'cohesive'. The ideas detailed below can be transferred to cases where the subgrade consists of cohesionless soil or rock, these two cases being, usually, easier to deal with than clays. Also, it is common to refer to the resilient modulus $\left(M_{R}\right)$ emanating from laboratory tests and resilient elastic stiffness $\left(E_{\mathrm{R}}\right)$ measured in the field, and these terms will be used herein.

\subsection{Design stage (measurement in the laboratory)}

Road foundation design is to be carried out as currently. 4,5 Subgrade CBR is to be measured in the laboratory for use in empirical design, while $M_{\mathrm{R}}$ will be measured for different sample states using the repeated load triaxial test (RLTT) for use in analytical design. In the future, once $M_{\mathrm{R}}$ values are well understood, the use of CBR design will cease to be of such importance, but for now it is considered necessary and prudent so that the engineering experience garnered from its use can be utilised. To limit the development of subgrade rutting, strength parameters from the RLTT will be determined. Using these data, designs will be carried out on the basis of limiting the stresses transmitted to the subgrade (i.e. a threshold stress approach). Design issues lie outside the scope of this paper (see reference 3 for advanced thinking on this issue).

Standard undisturbed (U100) samples of the subgrade will be taken during the site investigation for laboratory assessment using the RLTT, and will be used to determine:

(a) resilient elastic modulus $\left(M_{\mathrm{R}}\right)$ under a stress path appropriate to the design case being considered

(b) shear strength (herein termed $q_{\max }$ for convenience, but more properly defined as one half of the deviator stress at failure), being the maximum shear stress that the sample can sustain without failure

(c) threshold stress $\left(q_{\mathrm{thr}}\right)$, beyond which the accumulation of permanent deformation under repeated loading increases at a significantly higher (and therefore unacceptable) rate.

These parameters are described in more detail elsewhere. ${ }^{19,20}$ It is evident that $q_{\text {thr }}$ represents the most important strength parameter, as this is the level of shear stress that must be avoided by design of an adequate thickness (and stiffness) of sub-base/capping. However, $q_{\max }$ is specified on the assumption that there is a direct correlation between $q_{\text {thr }}$ and $q_{\max }$. Thus site testing of shear strength $\left(q_{\max }\right)$ should then ensure that the design, based on $q_{\mathrm{thr}}$, is not compromised and hence excessive subgrade rutting will not take place during construction. Where possible (e.g. construction at grade), the proposed site assessment tests for $E_{\mathrm{R}}$ and $q_{\max }$ should also be carried out at the time of the site investigation to provide a direct correlation between the laboratory and field data.

The subgrade should ideally be tested in four different states to provide the designer with a complete picture of the likely performance of the subgrade under different environmental and loading conditions. Thus the above properties will be determined from four sets of specimens:

(a) undisturbed samples (set 1), which represent the properties of the subgrade immediately after exposure without trafficking. Testing of these samples will yield the current in situ resilient modulus $\left(M_{R 1}\right)$ and strength parameters, which are likely to represent the best possible case achieved on site.

(b) samples that are remoulded at their natural water content (set 2), which will represent the most likely condition during construction $\left(M_{\mathrm{R} 2}\right)$ and reflect remoulding of the subgrade surface during construction

(c) undisturbed samples that are wetted to the equilibrium moisture content (i.e. wetted directly from their undisturbed state), using LR889 ${ }^{21}$ to determine an appropriate value (set 3). These samples will yield the in situ resilient modulus $\left(M_{\mathrm{R} 3}\right)$ and strength parameters that would occur in the long term if the subgrade remained free from disturbance during construction. It is assumed here that the drainage remains effective in the long term, and that the water content will remain stable once the equilibrium value has been reached.

(d) samples that are remoulded and wetted to the anticipated equilibrium moisture content (set 4). These will yield the design parameters $\left(M_{\mathrm{R} 4}, q_{\max 4}\right.$ and $\left.q_{\mathrm{thr} 4}\right)$ that represent the likely worst-case long-term modulus. 
There are a number of other scenarios for sample preparation that could be considered for different construction operations and sequences, and weather conditions. However, it is considered that the four sets described above will cover all circumstances within a conservative design approach. For example, if degradation of the subgrade is anticipated during construction, a set of samples prepared as suggested in set 4 could be used rather than set 2. Alternatively, if the installation (or lack) of drainage is considered to improve (or reduce) the material's performance during construction, sets 1 and 2 (respectively) will produce conservative parameters for design. (However, note that the likely short-term improvement in performance due to the installation of drainage in fine-grained soils will be limited.)

The specimen states listed above equate to those detailed in the flowchart shown in Fig. 2, which illustrates the procedure suggested herein. Note that the case of samples wetted to the anticipated equilibrium moisture content conditions directly from the undisturbed state was included in the research programme, as this represents the best-likely long-term case for design and as such should feature in an idealised philosophy. However, as expected, the state proved impractical to achieve, owing both to the time required for water equilibration and to the difficulty of obtaining uniformity of water content throughout the sample.

In the case of embankment construction a fifth set of samples would need to be tested: samples that are remoulded and wetted to an appropriate water content for compaction $\left(w_{\text {comp }}\right)$. In terms of the flowchart procedure, the samples obtained from site would have to be split into three batches, with the third being used to determine $M_{\mathrm{R} 5}, q_{\max 5}$ and $q_{\text {thr5 }}$ following remoulding and wetting to $w_{\text {comp }}$. The results of this testing would be used in place of the undisturbed samples (set 1) as they would represent the best-likely conditions prior to the laying of the capping or sub-base.

Ideally, the same testing regime should be carried out on the proposed capping and sub-base materials. However, the size (up to $125 \mathrm{~mm}$ ) and nature of the materials used as capping makes this impossible in practice, and even for the finergraded sub-base the difficulty of re-creating field conditions by laboratory compaction renders the results of little value as only a relative, as opposed to an absolute, measurement of performance parameters can be obtained. Attempts by Earland and Pike ${ }^{22}$ to determine an appropriate parameter (termed the peak shear stress ratio, PSSR) to limit rutting using the $300 \mathrm{~mm}$ shear box similarly proved to be of little value, as shear within the sample alone represents only part of the problem. The test therefore served only as an indicator of materials that exhibited exceptionally good or unacceptably poor internal shearing characteristics. Other approaches using shakedown theory ${ }^{23}$ have been suggested, although research in this area is still under way. Shakedown may be able to define a limiting stable/unstable 'threshold stress' for the granular materials similar to that defined for the subgrades above. These limiting values could be combined in the pavement design model and hence be used to control deformations.

Thus although the physical and chemical stability of the materials and their likely susceptibility to rutting, within the material itself, can be assessed via laboratory testing, the required performance parameters cannot be established with current equipment, and thus a full-scale trial section is needed to measure and/or validate performance.

\subsection{Assessment in-situ prior to construction}

Contractors will carry out a site trial at the beginning of construction work using the materials and construction methods proposed. The results of the site investigation will be used, where possible, to determine the most appropriate location (that is, a typical, or possibly poorest likely, section of the subgrade should be chosen). A complete programme of in situ testing will be performed on the surface of the exposed subgrade, and on the capping and sub-base layers after compaction and immediately prior to any further layer(s) being added, to determine the performance of the trial foundation. Consideration should be given to artificial saturation of part of the trial section and to further assessment testing to examine the likely effects of heavy rain prior to testing. Consideration could also be given to taking further undisturbed samples at the precise time and point of testing and to carrying out laboratory $M_{\mathrm{R}}$ and $q_{\max }$ tests in order that the correlation between laboratory and field data can be determined as accurately as possible.

In addition, a trafficking trial should be considered to provide assurance of resistance to permanent deformation. This is logical, as the performance requirement for resistance to permanent deformation is based on the measurement of rutting in the capping layer prior to sub-base construction, and on the premise that a proportion of the cumulative rutting seen at the surface will be manifest in the surface of the subgrade, as described later. The in situ tests on the subgrade will be used to provide a correlation with the laboratory data obtained as part of the site investigation, regardless of whether additional samples are taken at this stage.

Trials as part of this research have suggested that approximately 50\% of the surface rut is transferred to, and is thus manifest in the surface of, the subgrade, although this was found to be both material- and site-specific. Therefore the site construction trafficking trial, with local excavation of materials after trafficking to evaluate the proportion of subgrade rut transfer, will define surface rut limits. The control of rut formation requires further research related to material performance and design methodologies, although it is anticipated this will ultimately be assessable from design based on laboratory test data.

\subsection{Assessment in-situ during construction}

As construction proceeds, the subgrade should be tested in-situ for $E_{\mathrm{R}}$ and $q_{\max }$ immediately prior to capping placement. $E_{\mathrm{R}}$ is checked to ensure that adequate compaction of the overlying layer can be achieved, whereas $q_{\max }$ is checked to ensure that excessive subgrade rutting (i.e. $20 \mathrm{~mm}$ at the subgrade surface, being that considered to pose a risk of water ponding) will not occur. These are both essentially construction conditions, as it is assumed that $E_{\mathrm{R}}$ and $q_{\max }$ at the equilibrium condition will be considerably lower and yet transient deflection and subgrade rutting once the road pavement is in service is unlikely to be significant owing to the far smaller stresses transmitted. However, if the value of $E_{\mathrm{R}}$ and/or $q_{\max }$ falls below 


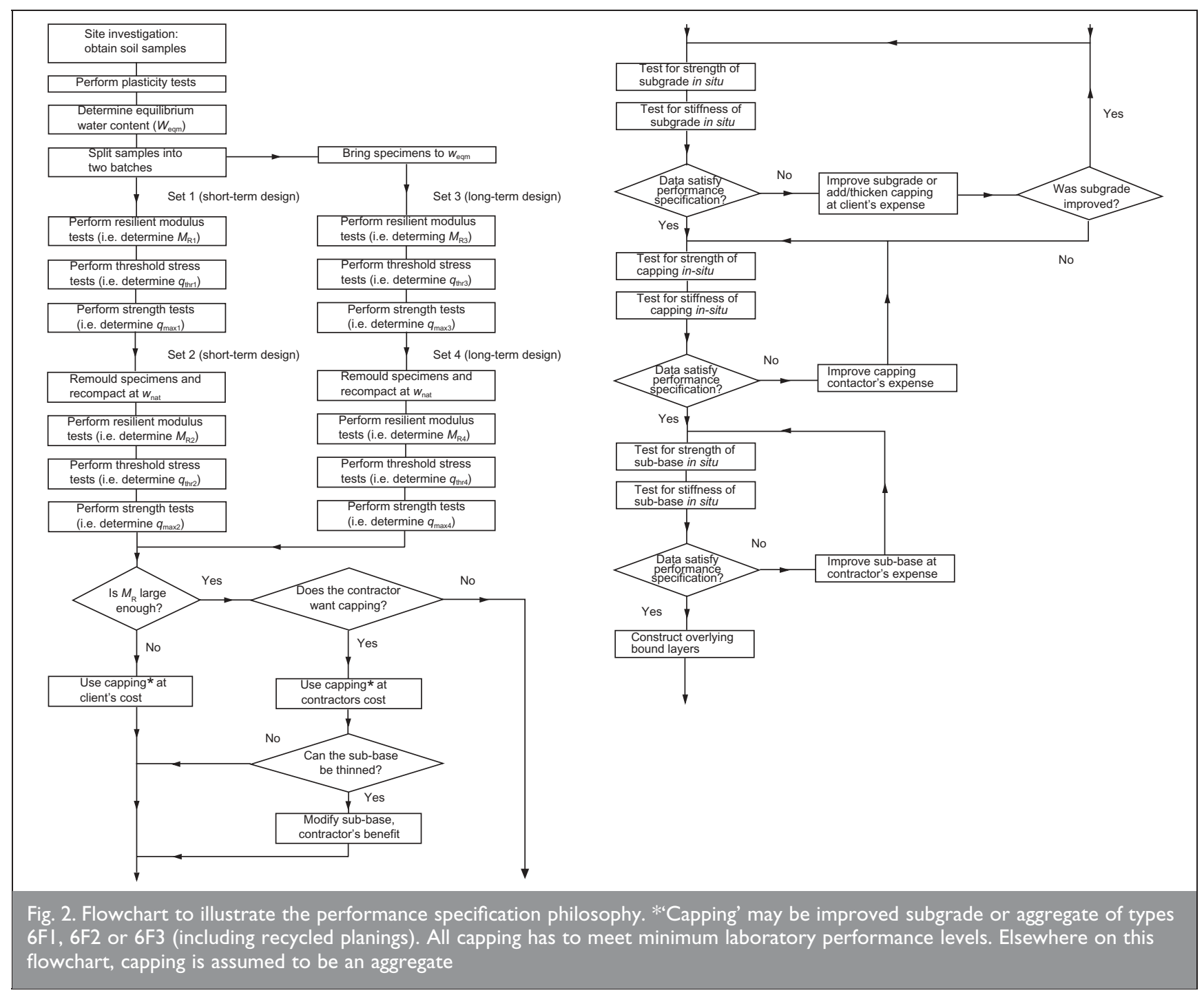

the design value, then the design will need to be amended (i.e. as construction takes place). This is equally true if the value of $E_{\mathrm{R}}$ and/or $q_{\mathrm{max}}$ falls below any other predetermined value, based on the laboratory data, which suggests that the equilibrium value of $E_{\mathrm{R}}$ or $q_{\max }$ will subsequently fall below the design value.

If either $E_{\mathrm{R}}$ or $q_{\max }$ falls below the requirements for site construction, then the area should be treated as a soft spot, as is traditional if a localised poor area is encountered on site, and additional excavation and addition/thickening of capping, or subgrade stabilisation, will be needed. If capping/additional capping/subgrade stabilisation proves necessary, it may be possible to take account of this in the design and reduce the thickness of the sub-base accordingly. However, the change in construction levels will complicate this procedure. A ratio of equivalence would be adopted for capping:sub-base based on their properties, following the same principle as is currently set out in DMRB. ${ }^{4}$ However, it could be argued that, if the subgrade competence is sufficiently poor to require the design to be changed, then no thinning of the sub-base should be allowed. It is envisaged that determination of the ratio of equivalence would be based on triaxial test data, but this lies outside the scope of the current project.
If the subgrade is satisfactory and no capping is to be constructed and no subgrade stabilisation is to take place, then no further testing is required until immediately prior to the placement of the bound layer(s), at which point the surface of the sub-base must be tested for compliance with target values. $^{24}$

If capping is to be constructed or subgrade stabilisation is to take place, then the top of the capping is to be tested for $E_{R}$ immediately prior to sub-base construction for compliance with target values to ensure that adequate compaction of the overlying layer can be achieved. In addition, the degree of rutting in the surface of the capping or stabilised layer is to be observed as the construction works proceed. The degree of rutting is checked both to ensure that the capping has not been disturbed to the extent where its compacted properties have been compromised and, primarily, to ensure that significant subgrade rutting has not taken place. Significant subgrade rutting can cause loss of stiffness and strength due to disturbance, and in the case of clay subgrades can result in ponding on the subgrade surface, which in turn can result in longer-term softening and weakening of the subgrade. The practice of including a sacrificial layer that is removed prior to final rolling (and assessment) remains an option to allow 
trafficking, provided that the cumulative rutting criterion is obeyed and damage to the lower portion of the capping or subgrade is avoided.

If the capping has an insufficient $E_{\mathrm{R}}$ then it must be recompacted, replaced by an acceptable capping, or otherwise brought up to an acceptable stiffness prior to sub-base construction. If the capping exhibits levels of rutting that indicate imminent failure, then the material should be replaced or, if $E_{\mathrm{R}}$ is sufficient, further trafficking should be avoided. Note that the rutting limit that is placed on the capping will have been determined from the trial to ensure that no significant subgrade rutting occurs, and that cessation of trafficking once the limit has been approached will not therefore result in significant subgrade damage. Careful monitoring will be necessary to ensure that the limit is not exceeded, however. Clearly, the better the subgrade, the greater the degree of trafficking that can take place.

Exactly the same principles apply to the sub-base as to the capping: that is, the surface of the sub-base should be tested for $E_{\mathrm{R}}$ immediately prior to the placement of the overlying bound layer(s), and surface rutting should be monitored to ensure that a limiting value is not reached. In this case the limiting value is set as an indicator of damage either to the sub-base itself or to the underlying materials, and ultimately the subgrade.

\section{DEVELOPMENT OF THE DRAFT PERFORMANCE SPECIFICATION}

This idealised specification suggests a variety of challenges to its implementation, and hence research needs. Accordingly the Highways Agency funded a recently completed programme of research aimed at producing an appropriate performance-based specification for capping and subgrade, and subsequently a second contract that examined the issues associated with implementation of the specification. The objectives of the research were:

(a) to identify the types of in situ test and test equipment that can produce reliable results when used to measure the properties of subgrade or capping as a pavement foundation for highways

(b) to produce a draft performance-based specification for subgrade and capping, and to suggest target values for the performance parameters

(c) to carry out a comprehensive programme of trials on subgrade and on capping, both on live sites and on specifically constructed trial sections, to demonstrate the validity of the performance specification.

The first objective built on the extensive previous research of the authors. ${ }^{7,14,25-29}$ The second objective has taken place over the last four years ${ }^{30-32}$ and has culminated in the generalised philosophy that is identified in this paper. This necessitated the setting of performance targets for capping and subgrade on the basis of previous testing. ${ }^{6,20}$ For the generalised philosophy equivalent targets are needed for the sub-base. ${ }^{24}$ The results of the initial work to test the efficacy and robustness of the specification ${ }^{32,33}$ have confirmed that the approach is valid, but that a synthesis of the results is required to ensure that the specified procedures and target values are correct. These issues are intimately related to road construction practice, and in particular to compaction technology, ${ }^{34}$ both of which must be considered in detail when interpreting the specification philosophy presented herein. It was identified early on in the project that the performance specification developed from this research would need to undergo a phased introduction into practice. This was considered necessary both to engender confidence in the new techniques and to make best use of the considerable empirical experience that has been generated over many years with the traditional means of design and performance assessment. This provides a sensible way forward for the work, but equally makes provision for practical experience to be incorporated into the final version of the specification.

\section{CONCLUDING SUMMARY}

Recent advances in laboratory and in situ testing have enabled a move from a recipe specification to a performance-based specification for road foundation materials to be developed. The parameters that need to be assessed both for design and for proof of performance are resilient elastic modulus, shear strength, and resistance to permanent deformation. In addition, at least in the short term, CBR should also be measured so that the long experience of its use in practice can be utilised in parallel with the new measurements. For design, these parameters should ideally be measured on samples of the individual materials that comprise the road foundation. However, the size and nature of capping and sub-base materials make this currently impractical, and thus laboratory performance tests can be carried out in full only on samples of the subgrade. These tests should ideally be undertaken on undisturbed and remoulded samples of soils at their current natural water and projected equilibrium water contents so that a range of values can be considered in design. Indirect tests for capping and sub-base durability and tendency to shearing, and therefore internal rutting, can however be performed.

To ensure adequate field performance, the strength and stiffness of the subgrade should be tested on exposure and/or immediately prior to capping (if necessary) or sub-base construction. Similarly the finished capping and sub-base surfaces should be tested for composite resilient elastic modulus to confirm that the design requirements have been met and so that compaction of the overlying layer(s) can be carried out adequately. It is not currently possible to measure directly a parameter that indicates the composite resistance to surface deformation, and consequently the accumulation of surface rutting should be monitored and kept below a limiting value, dependent on the thickness of the combined capping/ sub-base. This is to ensure that the material layer(s) are not compromised as a result of internal shearing, and so that significant subgrade surface rutting is avoided.

As a range of testing devices exists for the assessment of pavement foundation layers in situ, it is recommended that a pre-construction trial be carried out to establish correlations between laboratory and field measurements, as well as to prove the efficacy of the proposed construction materials and methods used. It is strongly recommended that trafficking be carried out once the trial sections have been constructed and tested so that likely performance can be accurately determined. The pre-construction trial will give both the client and the 
contractor confidence that the works will be constructed to an adequate standard.

A comprehensive set of trials on live construction sites and specifically constructed trial road foundations has been carried out in support of the philosophy, and detailed recommendations for the devices and procedures to be used and the target values that need to be achieved have been reported. ${ }^{9}$ This work has, however, proved that the philosophy contained herein provides a sound and fair basis for the specification of road foundation, whether constructed from traditional materials under traditional loadings or from novel materials under revised loadings.

\section{ACKNOWLEDGEMENTS}

The authors gratefully acknowledge the financial support of the Highways Agency and the technical input to the work of Mr R. K. W. Lung and his colleagues. This work is part of a larger project that is being carried out by a consortium of Scott Wilson Pavement Engineering Limited and Birmingham, Loughborough, Nottingham and Nottingham Trent Universities. The valuable input of various members of these organisations is gratefully acknowledged. The opinions expressed are solely those of the authors and do not necessarily represent those of the UK Highways Agency.

\section{REFERENCES}

1. BROWN S. F. Soil mechanics in pavement engineering. Géotechnique, 1996, 46, No. 3, 383-426.

2. RoAD ReSEARCH LabORATORY. A Guide to the Structural Design of Pavements for New Roads. Road Research Laboratory (RRL), Crowthorne, 1970, Road Note 29, 3rd edn.

3. BRown S. F. and DAWSON A. R. Two stage mechanistic approach to asphalt pavement design. Proceedings of the 7th International Conference on Asphalt Pavements, Nottingham, 1992, 16-34.

4. DePARTMENT OF TRANSPORT. (1994) HD 25/94 foundations. In Design Manual for Roads and Bridges, Vol. 7, HMSO, London, 1994.

5. Powell W. D., Potter J. F., Mayhew H. C. and NunN M. E. The Structural Design of Bituminous Roads. Transport Research Laboratory, Crowthorne, 1984, TRL LR1132.

6. ChADDock B. C. J. and Brown A. J. In-situ tests for road foundations. Proceedings of the 4th International Conference on Unbound Aggregates in Roads, Nottingham, 1994, 259-269.

7. Fleming P. R. and Rogers C. D. F. Assessment of pavement foundations during construction. Proceedings of the Institution of Civil Engineers, Transport, 1995, 111, No. 2, $105-115$.

8. Rogers C. D. F. General report: in-situ assessment. Proceedings of the 4th International Conference on Unbound Aggregates in Roads, Nottingham, 1995, 249-257.

9. Fleming P. R., Rogers C. D. F. and Frost M. W. Performance Based Specification for Subgrade and Capping: Research Reports. Scott Wilson Pavement Engineering Ltd, Nottingham, 1999, Final Reports to the Highways Agency (six research reports in three volumes).

10. Croney P. and Croney D. The Design and Performance of Road Pavements, 3rd edn. McGraw Hill, New York, 1997.
11. Brown S. F., O'ReIlly M. P. and LOACH S. C. The relationship between California Bearing Ratio and elastic stiffness for compacted clays. Ground Engineering, 1990, 23, No. 8, 27-31.

12. Hight D. W. and Stevens M. G. H. An analysis of the California Bearing Ratio test in saturated clays. Géotechnique, 1982, 32, No. 4, 315-322.

13. Kleyn E. G. and SAvage P. F. The application of the pavement DCP to determine the bearing properties and performance of road pavements. Proceedings of the 1st International Conference on the Bearing Capacity of Roads and Airfields, Trondheim, 1982, 238-246.

14. Dawson A. R., Cheung L. W., Brown S. F., Rogers C. D. F. and FLEMING P. R. Requirements of Laboratory Design and Field Assessment Tests for Pavement Foundations.

Transport Research Laboratory, Crowthorne, 1990, TRL Working Paper WP/PE/75.

15. Fleming P. R. Impact Assessment of Layered Granular Materials. PhD thesis, Loughborough University, UK, 2000.

16. Fleming P. R. and Rogers C. D. F. Assessment of permanent deformation characteristics of four granular pavement foundation materials in situ. Proceedings of the 4th International Conference on Bearing Capacity of Roads and Airfields, Minneapolis, 1994, 2, 967-987.

17. Fleming P. R., Rogers C. D. F. and Brown A. J. Permanent deformation characteristics of granular materials for highway construction. Proceedings of the 4th International Conference on Unbound Aggregates in Roads, Nottingham, 1995, 271-279.

18. Rogers C. D. F., Glendinning S. and DiXon N. Lime Stabilisation. Thomas Telford, London, 1996.

19. Fleming P. R., Rogers C. D. F., Dawson A. R. and Frost M. W. Subgrade equilibrium water content and resilient modulus for UK clays. Proceedings of the International Symposium on Subdrainage in Roadway Pavements and Subgrades, Granada, 1998, 359-366.

20. Fleming P. R., Rogers C. D. F. and Frost M. W. Performance parameters and target values for construction of UK road foundations. Proceedings of the 5th International Conference on the Bearing Capacity of Roads and Airfields, Trondheim, 1998, 1491-1502.

21. BlaCK W. P. M. and LISTER N. W. The Strength of Clay Fill Subgrades: Its Prediction in Relation to Road Performance. Transport Research Laboratory, Crowthorne, 1979, TRL LR889.

22. EARland M. G. and PiKe D. C. Stability of Gravel Sub-Bases. Transport Research Laboratory, Crowthorne, 1985, TRL RR64.

23. LEKARP F. and DAWSON R. Modelling permanent deformation behaviour of unbound granular materials. Construction Building Materials, 1998, 12, No. 1, 9-18.

24. Nunn M. E., Brown A. J., Weston D. and Nicholls J. C. Design of Long Life Flexible Pavements for Heavy Traffic. Transport Research Laboratory, Crowthorne, 1997, TRL Report 250.

25. Boyce J. R., Fleming P. R., King G., Rogers C. D. F. and CoBBE M. I. A new variable impact test for pavement foundations. Proceedings of the 3 rd International Conference on Bearing Capacity of Roads and Airfields, Trondheim, Norway, 1990, 185-194.

26. King G., Fleming P. R., Boyce J. R. and Rogers C. D. F. A new variable impact test for low-volume roads. 
Transportation Research Record 1291, 1991, 2, 204-211 (also presented to International Conference on LowVolume Roads, New Orleans, USA, May 1991).

27. Rogers C. D. F., Brown A. J. and Fleming P. R. Elastic stiffness measurement of pavement foundation layers. Proceedings of the 4th International Conference on Unbound Aggregates in Roads, Nottingham, 1995, 331-338.

28. Fleming P. R., Frost M. W. and Rogers C. D. F. A comparison of devices for measuring stiffness in situ. Proceedings of the 5th International Conference on Unbound Aggregates in Roads, Nottingham, 2000, 193-200.

29. Rogers C. D. F., Fleming P. R. and Frost M. W. Stiffness behaviour of trial road foundations. Proceedings of the 5 th International Conference on Unbound Aggregates in Roads, Nottingham, 2000, 231-237.

30. Lung R. K. W., Johnson P. D. and Rogers C. D. F.
Development of a performance based specification for capping and subgrade for UK roads. Proceedings of the 2nd European Road Research Conference, Brussels, 1999.

31. Fleming P. R., Frost M. W., Rogers C. D. F., Armitage R. J. and Tном N. H. A performance based specification for road foundation materials. Proceedings of Quarry 2000, Bristol, 2000, F1-F15.

32. Fleming P. R., Rogers C. D. F. and Frost M. W. Assessment of a performance specification approach for pavement foundations. Transportation Research Record 2001, 1757, $100-110$.

33. Frost M. W. The Performance of Pavement Foundations During Construction. PhD thesis, Loughborough University, UK, 2000.

34. PARSons A. W. Compaction of Soils and Granular Materials: A Review of Research Performed at the TRL. HMSO, London, 1992.

Please email, fax or post your discussion contributions to the secretary by I February 2005: email: mary.henderson@ice.org.uk; fax: +44 (0)20 7799 1325; or post to Mary Henderson, Journals Department, Institution of Civil Engineers, I-7 Great George Street, London SWIP 3AA. 